\title{
FIRE INVESTIGATION IN AN ITALIAN WASTE TREATMENT PLANT: LESSONS LEARNED AND FUTURE DEVELOPMENT
}

\author{
GIOVANNI ROMANO \& ALFREDO ROMANO \\ RSM Romano Safety Management STP, Osio Sotto (BG), Italy
}

\begin{abstract}
In June 2017, in the north of Italy, a serious fire occurred in a waste treatment plant and involved the entire warehouse. Romano Safety Management (RSM) was charged with reconstructing the evolution of the fire, in order to establish whether the sequence of events leading up to the accident could be compatible with developing times of the accident. Documental evidence has collected in the accident place, as well as proofs of operators and rescuers who provided support on-site. The fire, the structure and materials composing the warehouse were rebuilt using "Fire Dynamic Simulator" (National Institute of Standard and Technology) and "PyroSim" (Thunderhead Engineering). RSM carried out a three-dimensional simulation of the fire, assuming that the origin of the fire was provoked by an accumulation of crushed waste of mattresses and considering interferences with the other parts of the warehouse, where different materials (wood, rubber, etc.) were stocked. According to the results, considering the ignition temperature of products and the presence of concrete separation walls, RSM concluded that the simulation of fire development was congruent and compatible with the development times of the fire. At the end, it was demonstrated that there were no active or passive fire-prevention protections inside the warehouse; these protections, jointly with a better operative management of the warehouse, could have avoided the fire development. In the last few years, many similar fires occurred in Italy and, for that reason, the Italian Ministry of Environment recently issued the first version of a "Guideline" according to risk management. These accidents and the results of the analyses will probably lead to a review of the fire-prevention design criteria of these plants.
\end{abstract}

Keywords: fire investigation, waste treatment plant, fire safety engineering, performance approach, fire risk analysis.

\section{INTRODUCTION}

The purpose of this article is to share the experience gained by RSM (Romano Safety Management) in "fire investigation". This is a fire that developed inside an Italian industrial plant treating various types of waste. Some details are omitted because a judicial inquiry is still under way. RSM had been commissioned by its Client to proceed with a simulated "reconstruction" of the evolution of the fire. In particular, the propagation speed, intensity and persistence of the flames were investigated, in order to verify whether the fire was compatible with the materials present at the time of the accident and to verify the ignition condition of combustible material placed in the warehouse.

The reconstruction of the simulation model, and in particular the materials inside the compartments, was obtained thanks to the elements provided by the Client and the verification of the evolution of the fire through interviews with staff, paper documentation and photographs.

The fire simulation was performed through the calculation models called "Fire Dynamics Simulator" and the "PyroSim" interface. The definition of the fire scenario assumes a fundamental role in the characterization of the fire itself and its results; in the case under examination, RSM predefined it on the basis of the elements collected and not through a risk analysis that is usually carried out upstream the identification of the scenario itself. 
The purpose of the analysis was to clarify some aspects of the development of the fire, in order to evaluate appropriate improvement actions to prevent similar accidents, and in particular:

a) if the fire in the warehouse was congruent in terms of propagation speed and intensity;

b) if the fire in the outside container of combustible material was compatible with the development of the fire inside the warehouse that would generate temperatures of degradation of the product contained therein and consequent ignition;

c) once confirmed the non-compatibility, what could be the probable causes that led to the fire.

\section{SUMMARY OF THE ACCIDENT AND IDENTIFICATION OF THE CRITICAL PARAMETERS OF REFERENCE}

The fire developed from a combination of products deriving from the treatment of combustible materials (it has to be underlined again that some details are deliberately omitted from the present). For the purposes of the present, the potential causes of ignition have not been analysed, but the sequences of ignition of the other materials in the warehouse have been analysed. The critical points of the evolution are the following:

Time 0:

Time $180 \mathrm{~s}$ : an operator tried to "isolate" the inflamed material from the one

the operators, which were present, detected a beginning of fire during the normal treatment operation. not yet affected by the fire, by taking the inflamed part of the pile and bringing it outside, the operation partially succeeded.

Time $300 \mathrm{~s}:$ the fire was extended to the compartment near the pile of combustible material and, in the meantime, the internal emergency team was operative to prevent the fire as much as possible.

Time 300-600 s: the vehicles inside the warehouse were moved outside from the side exit at about 40 metres.

Time $600 \mathrm{~s}:$ In the time between 300 and 600 seconds, the fire extended to the other sectors where there were other combustible materials.

Time 15-20 minutes: all the piles of rubber products were on fire and the warehouse was completely full of smoke.

\section{CALCULATION MODELS USED}

The fire simulations described in the previous paragraph were carried out by using the Fire Dynamics Simulator calculation model (known as "FDS", acronym used below) by the National Institute of Standards and Technology (NIST, USA).

FDS is a Computational Fluid Dynamics calculation model ("CFD"), specifically developed for fires, that uses LES [1] techniques ("Large Eddy Simulation"). This model permits us to foresee the heat conditions resulting from a fire in a compartment [2], [3].

A CFD calculation model requires that the compartment or building of interest (intended as a series of compartments) be subdivided into control volumes (computational cells) in the form of a parallelepiped or, better, cubic. The CFD calculation model estimates the density, speed, temperature, pressure and concentration of the chemical species in each cell.

Based on the laws of conservation of mass, moment, species and energy, the model outlines the generation and movement of fire gases. FDS employs the material characteristics of the elements of the survey domain, in order to estimate the growth and spread of the fire. A complete description of the model can be found in the documentation annexed to it (see previous notes). 
The ability of the FDS model to predict accurately the temperature and speed of the gases developed by the fire was previously evaluated by the NIST by conducting appropriate experiments, both on a reduced scale and in a real scale and the subsequent analysis of the data from the field. For relatively simple flows caused by the fire, such as in the case of naked flames and flows through passages, doors and windows, the FDS predictions are compatible with the experimental uncertainty of the values measured in the experiments conducted over the years by NIST (since 1998).

In large-scale test fires, temperature predictions through the use of FDS showed values characterized by a difference of $15 \%$ compared to the actual measured temperatures, while the Heat Release Rates predicted by a difference of $20 \%$ of the measures taken.

\section{GEOMETRIC RECONSTRUCTION AND CHARACTERISTICS OF PRODUCTS IN THE WAREHOUSE}

The geometric reconstruction of the building, which is necessary for the modelling of the fire scenario, was carried out by using the PyroSim 2017 software. We proceeded to a three-dimensional survey with laser scanning technology and to a subsequent processing of the point cloud through 3D processing software. Fig. 1(a) shows a screenshot of the point cloud, and Fig. 1(b) the three-dimensional model subsequently imported into PyroSim.

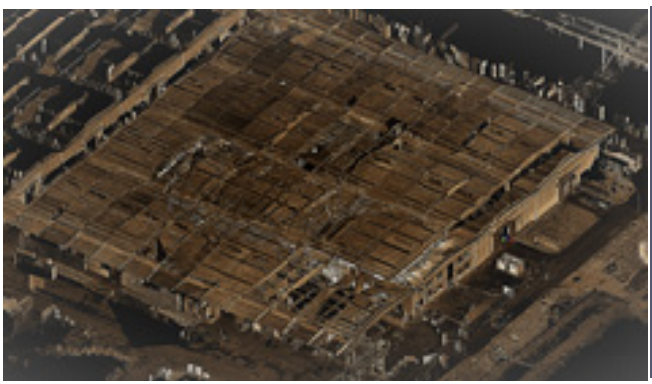

(a)

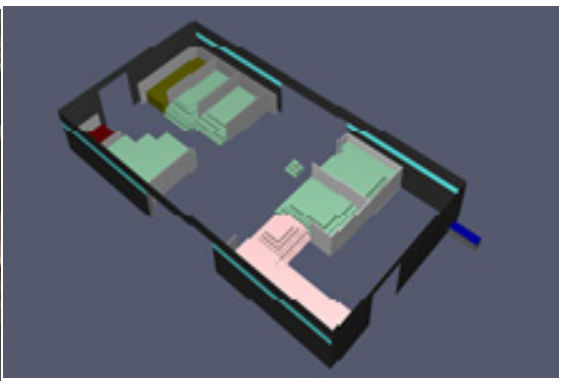

(b)

Figure 1: (a) Point Cloud from laser scanning; (b) 3D model in PyroSim. Inside the building, there were no fire-fighting compartments.

The warehouse was equipped with a bird mesh screen that, in the simulation, was considered as a propylene net with density of $1 \mathrm{~kg} / \mathrm{m}^{3}$ and melting temperature of $160^{\circ} \mathrm{C}$.

The HRRPUA parameter (Heat Release Rate Per Unit Area) represents the heat flow developed by combustion per unit area.

Table 1 shows the main characteristics of the construction materials.

Table 1: Characteristics of construction materials.

\begin{tabular}{|l|c|c|}
\hline Material & Density $\left(\mathrm{kg} / \mathrm{m}^{3}\right)$ & Heat conductivity $(\mathrm{W} / \mathrm{m} \mathrm{K})$ \\
\hline New Jersey barriers & 2280 & 1.8 \\
\hline Sandwich panels & 40 & 0.02 \\
\hline Polycarbonate glasses & 1380 & 0.2 \\
\hline
\end{tabular}

In the attic, there was also a polypropylene mesh. Table 2 below shows the typical data of the materials used for modelling the fire scenario. 
Table 2: Typical data of materials used for the simulation.

\begin{tabular}{|l|c|c|c|}
\hline Material & $\begin{array}{c}\text { Density } \\
\left(\mathrm{kg} / \mathrm{m}^{3}\right)\end{array}$ & $\begin{array}{c}\text { Auto-ignition } \\
\text { temperature }\left({ }^{\circ} \mathrm{C}\right)\end{array}$ & $\begin{array}{c}\text { HRRPUA (heat release rate } \\
\text { per unit area) }\left(\mathrm{kW} / \mathrm{m}^{2}\right)\end{array}$ \\
\hline Material 1 & 50 & 250 & 500 \\
\hline Material 2 & 640 & 450 & 200 \\
\hline Material 3 & 640 & 400 & 200 \\
\hline Material 4 & 900 & 350 & 300 \\
\hline Rubber & 1400 & 400 & 500 \\
\hline
\end{tabular}

\section{IDENTIFICATION OF FIRE SCENARIO}

The study was carried out by a three-dimensional fire simulation, assuming that the fire source originated from a pile of combustible waste, placed near the entrance of the warehouse, formed after crushing operations. According to the reconstruction carried out, the initial fire ignition started from the burning of the crushed pile.

The simulation was carried out without considering any fire mitigation (it should be noted that, after about 300 seconds, the internal emergency team intervened to start the first cooling operations, waiting for the Fire Brigade arrival).

\section{FIRE SIMULATION}

The result of the three-dimensional simulation with the FDS/PYROSIM calculation model consists of a video that allows checking the development of the fire according to time and temperature profiles on the walls of the warehouse and on the virtual plans introduced during the input phase, in particular on the caissons and on the accumulation of the products. The analysis of the video highlighted the following interesting points, to which we extracted "still images" with related comments. The $33 \mathrm{~s}$ still image (Fig. 2) shows that the accumulation of combustible material is partially ignited but it has not yet initiated and propagated to the compartment next the combustible material.

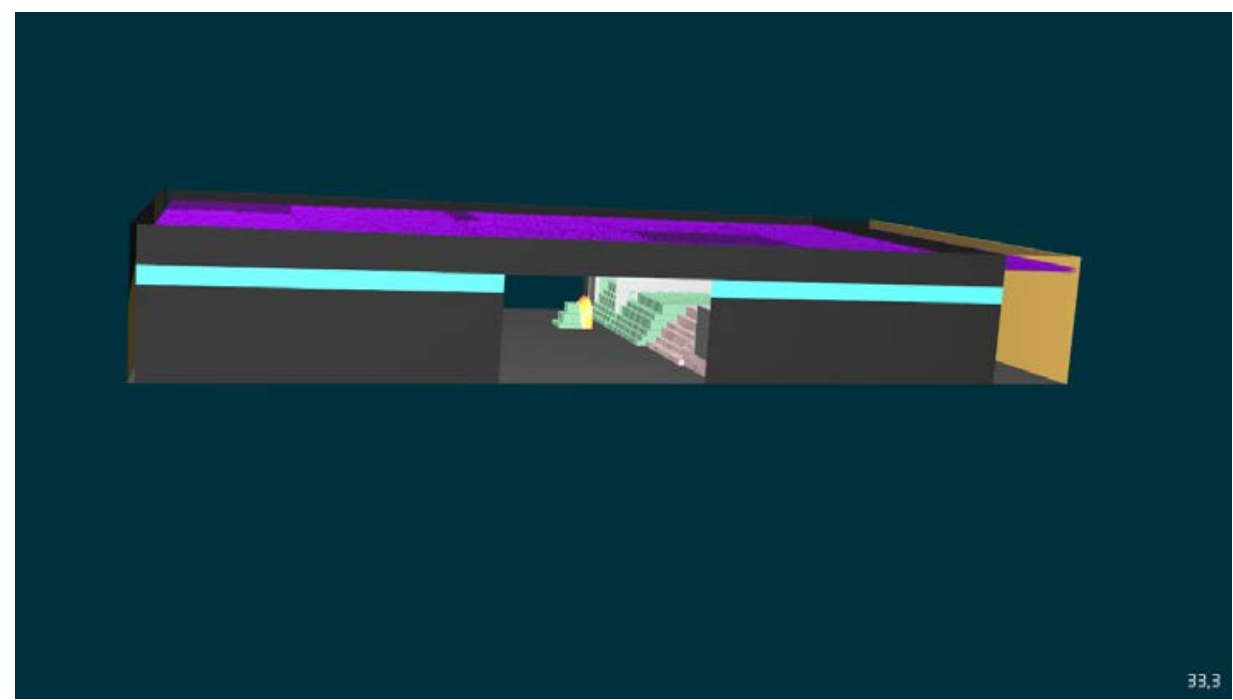

Figure 2: Accumulation of fire crushed material (Time $33 \mathrm{~s}$ ). 
The accumulation of crushed material, from which the fire began, ignited the compartment next to the combustible material on the wall side of the warehouse: Fig. 3 shows the initial instants of the fire, in which the temperatures are still quite basic (compare the colour of the wall and the temperature scales).

Fig. 4 shows that the fire is propagating to the compartment next to combustible material after about 147" and, therefore, is in accordance with what was reported in the description of the accidents. Fig. 5 shows the fire involving the whole warehouse.

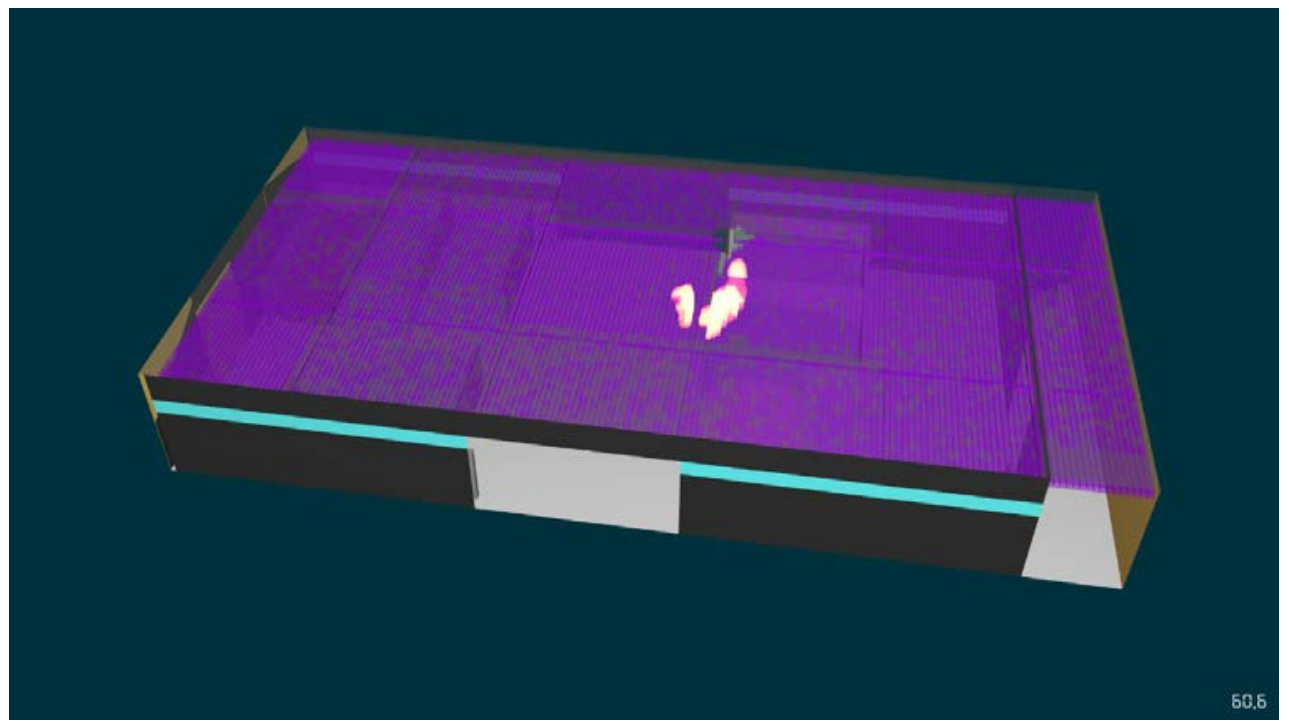

Figure 3: Accumulation of fire combustible material (Time $60 \mathrm{~s}$ ).

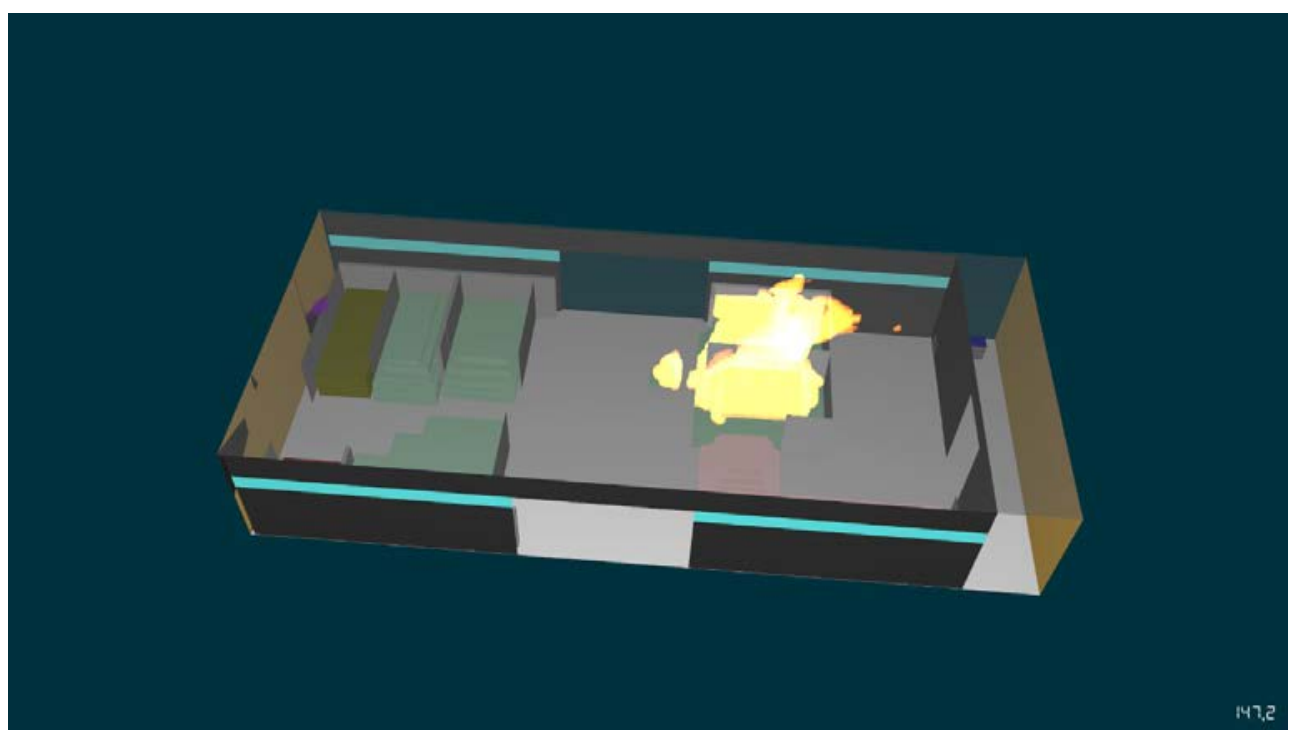

Figure 4: Propagation of fire to compartments (Time $147 \mathrm{~s}$ ). 
The development of the fire is congruent with the available elements. The temperature profile detected with a virtual plane on the tire caisson leads to low temperature values not able to develop the degradation of the rubber, in order to facilitate ignition.

The fire (Fig. 6) continues even if the piles of crushed material to the next compartments begin to decrease in consistency and the flames are lowered with consequent reduction of the temperatures; it should also be noted that in the compartment 2 (completely wood) there is no ignition.

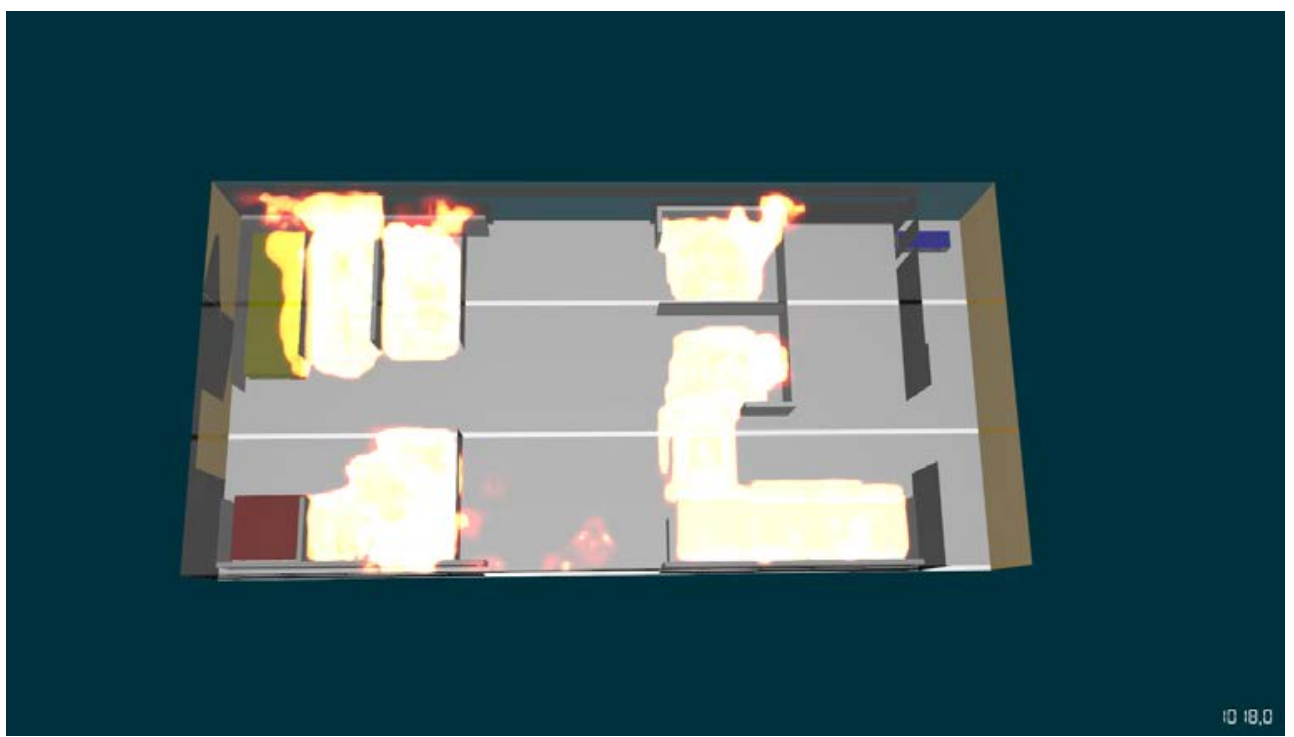

Figure 5: Fire involving the entire warehouse (time $1000 \mathrm{~s}$ ).

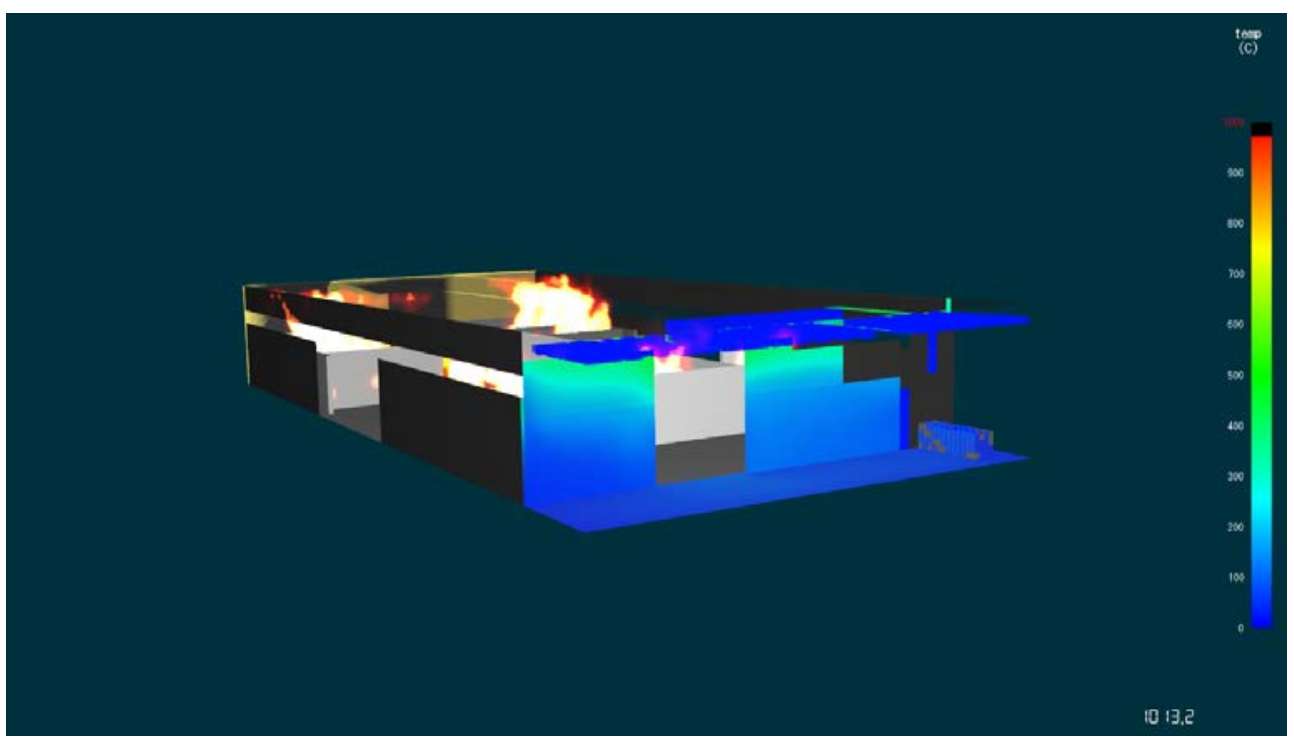

Figure 6: Temperature profile (time $1000 \mathrm{~s}$ ). 


\section{RESULTS ACHIEVED}

The simulation demonstrated that the development of the fire in the outer caisson of combustible material was not due to the presence of flammable products that could be a source of possible secondary ignition. The simulation also showed that the development of the fire inside the caisson was not compatible with the temperature reached inside the warehouse. This statement is further strengthened by the conservative assumptions upstream of the simulation, which aggravated the incidental scenario with a pile of additional fuel product close to the combustible material, from which the ignition began and it did not take into account the mitigation measures carried out by the internal emergency team and the subsequent intervention of the Fire Brigade.

The videos of the three-dimensional simulation of the fire and the sequence of photos above confirm that inside the caisson, a temperature causing a decomposition of the rubber and leading to hydrocarbon vapours, which usually release from this type of product, was not reached.

Actually, however, it was found that the fire was there and, then, it is necessary to proceed with some reflections, in order to understand and reconstruct what happened and why the results of the simulation are quite congruent with the development of the fire within the warehouse and, instead, it seems not considering the caisson placed outside.

The possible hypotheses that may have led to this lack of characterization can be attributed, in our opinion, to the state of the areas on the caisson-side that, in the modelling, was considered "empty" of materials from the compartments next to the origin of the ignition up to the wall bordering the caisson and the area surrounding the caisson itself.

\section{FURTHER DEVELOPMENT}

In the last few years, many similar fires occurred in Italy and, for that reason, the Italian Ministry of Environment has recently issued a first version of a "Guideline" according to risk management.

These accidents and the results of the analyses will probably lead to a review of fire-prevention design criteria of these plants, such as firefighting plant (fixed or mobile), gas or fire detection system and a critical review of Emergency Internal Plan.

During the analysis it was found that, at a design level, some measures could be taken, such as for example passive protection or the insertion of a dedicated sprinkler system, even limited to a portion of the warehouse.

The fire and/or smoke detection could be considered even if the intervention of the team was timely and the high fire risk processes are carried out during the personnel supervision.

\section{REFERENCES}

[1] McGrattan, K. et al., Fire dynamics simulator (version 5) technical reference guide. NIST Special Publication 1018-5NIST in cooperation with VTT Technical Research Centre of Finland, National Institute of Standards and Technology, US Department of Commerce, 2008.

[2] McGrattan, K.B., Hamins, A. \& Stroup, D., Sprinkler, Smoke \& Heat Vent, Draft Curtain Interaction - Large Scale Experiments and Model Development, NISTIR 6196-1, National Institute of Standards and Technology: Gaithersburg, 1998.

[3] McGrattan, K.B., Baum, H., Rehm, R. \& Large, G.E., Simulations of smoke movement. Fire Safety Journal, 30, pp. 161-117, 1998. 